\title{
Mathematics Societies and AAAS: Natural Partners?
}

\section{Sophia D. Merow}

It is a truth universally acknowledged (by those who pause to think about it, anyway) that mathematics is "under the radar" in the American Association for the Advancement of Science (AAAS), its profile in the multidisciplinary scientific society lower than perhaps befits what Gauss called the "queen of the sciences." AAAS, likewise, goes about its science-advancing business largely unheeded by much of the mathematics community.

Which is not to say that mathematics doesn't have advocates within AAAS, and vice versa. Indeed, the would-be bridge-builders who showed up for the business meeting of the AAAS Section on Mathematics (Section A) at the Association's annual meeting in DC in February packed the assigned space so snugly that one of the morning's presenters forewent the easel paper procured for him. "There's no way I'm going to get up there without falling on somebody," he explained. During its three hours together, the capacity crowd discussed how to increase the involvement of mathematicians-and thus the visibility of mathematics-in AAAS.

\section{Everybody's $\boldsymbol{n}^{\text {th }}$ Society (where $\boldsymbol{n}>\mathbf{1}$ )}

Jennifer Pearl, who directs AAAS's Science \& Technology Policy Fellowships program (which she wrote about in the April 2019 Notices, see https://bit. 7y/2TVm0QC), knows that AAAS can be a hard sell, and not just to mathematicians. "One of the challenges is that it's everybody's second society," she said. A specialist in ant behavior is likely to join the Entomological Society of America before AAAS; most mathematicians probably prioritize membership in at least one of MAA, SIAM, and AMS (not to mention the

Sophia D. Merow is Special Projects Editor and Notices assistant. Her email address is merow.notices@gmai1.com.

For permission to reprint this article, please contact: reprint-permission aams.org.

DOI: https://dx.doi.org/10.1090/noti 1886 other professional societies under the CBMS umbrella) above AAAS membership.

Given its areas of emphasis, though, Section A Secretary Reinhard Laubenbacher believes that AAAS complements mathematical sciences professional societies nicely. "It's all about outreach, and all about policy-all important issues for the math community," he told business-meeting attendees. " "So AAAS is a natural partner." Former AMS president-and former Section A chair-Eric Friedlander likewise cites AAAS's advocacy activities as a reason for mathematicians to consider membership (see statement, p. 913).

\section{Fellows}

Friedlander and the presenter who didn't risk a trip to the easel, C. T. Kelley, were elected AAAS Fellows in 2018. Of the 416 fellows in the 2018 class, six (see box below) belong to Section A. For comparison, Section U (Statistics) boasted seven fellows, Section R (Dentistry and Oral Health Sciences) five, and Section G (Biological Sciences) 112. The number of fellows allotted to each of AAAS's twenty-four

\section{AAAS Section on Mathematics 2018 Fellows \\ Eric M. Friedlander, University of Southern California \\ Ilse C. F. Ipsen, North Carolina State University \\ George Em Karniadakis, Brown University \\ C. T. Kelley, North Carolina State University \\ David E. Keyes, King Abdullah University of Science and Technology (Saudi Arabia) \\ Yi Li, John Jay College of Criminal Justice, CUNY}




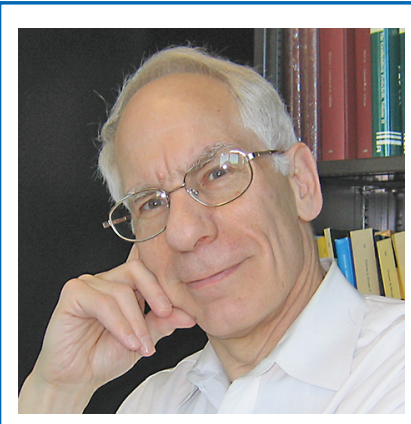

Why belong to AAAS? One reason is to read about scientific developments in Science magazine and to attend broad-based scientific meetings, thereby broadening a member's intellectual interests. Another is that AAAS is an important advocate for science. With the backing of its broad membership, AAAS speaks loudly in favor of government funding of science, supports rationality in public discourse, and promotes issues of common interest to scientists such as diversity and human rights.

-Eric Friedlander, Fellow of the AMS (2012), Fellow of AAAS (2018), President of AMS (2011-2012), Chair of AAAS Math Section (2015-2016)

sections depends on section membership: Only those who have been AAAS members without lapse for the four-year period prior to nomination are eligible to be fellows, and no section's nominees in any given year can number more than 0.4 percent of its primary membership.

The 2019 Section A business meeting included presentations from fellows for the first time. Kelley told tales of applying optimization and nonlinear solvers across disciplines. Yi Li credited color blindness with getting him into mathematics. ("To be an engineer," he said, "you had to be able to tell green from red.") David Keyes capped off an "ode-like" homily on the beauty, utility, and community of mathematics with an actual (self-authored) ode titled "Anthematica." The final couplet: "At AAAS do mathematics and her partners meet | The fellowship of pilgrims here is infinitely sweet."

\section{Agencies Fight over These Folks}

Another kind of AAAS fellow also addressed the gathering. Having received a $\mathrm{PhD}$ in mathematics (with an emphasis in algebra and combinatorial topology) from the University of Oregon in 2014, Tyler Kloefkorn is spending 2017-2019 as a AAAS Science and Technology Policy Fellow in the NSF's Division of Information and Intelligent Systems. Kloefkorn isn't always sure how much math to dish out when. "The other day I was trying to explain what a simplicial complex was to somebody who was trying to understand topological data science," he said. "I don't know that I was all that helpful." But he does appreciate that the fellowship allows him to explore alternatives to "very very very hard to get" assistant professor jobs.

Jennifer Pearl, herself an alumna of the program she now directs, agrees that seeing how one's mathematical knowl- edge and sensibility play out in a Congressional office or one of the federal agencies can open up a "completely different world" of possibilities. "There are some individuals that want to do the symplectic geometry research and stay very focused on the technical part," said Pearl, whose own dissertation work was in symplectic geometry. But the fellowship offers "opportunities for folks who want to broaden what they're looking at." Pearl's comments jibe with 2012-2013 AMS/AAAS Congressional Fellow Carla Cotwright-Williams's reasons for pursuing the fellowship (see statement below).

And the agencies and offices in DC are, to hear outgoing Section A chair Deborah Lockhart of the National Science Foundation tell it, eager to host any symplectic geometers or combinatorial topologists or the like who are keen to bring scientific expertise to the federal sector to inform better policy making. "Agencies fight over these folks," Lockhart said of fellowship applicants.

Pearl reported that in 2018-2019 there were many more offices that wanted fellows than there were qualified final-

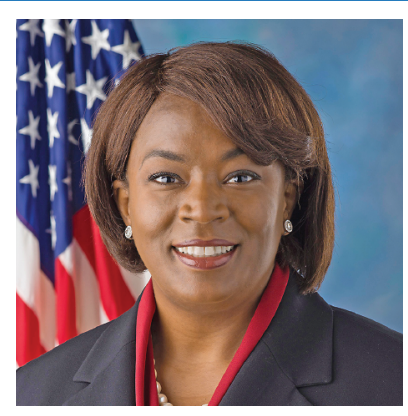

For over 40 years, AAAS Science and Technology Policy Fellows have worked alongside congressional staffers and federal personnel helping to inform a vast number of S\&T policy issues ranging from education to energy, from cybersecurity to water quality. Mathematicians apply their PhD-level analytical skills to help find solutions to the toughest problems faced by the US Congress and federal agencies.

I've had fellow mathematicians ask, "Why would you want to do that fellowship?" My response is a simple one. It is important to me to use my knowledge and skills in a different way...in a way that I might have a broader impact on the world around me. The fellowship is a unique opportunity to learn and contribute outside of some paths taken by $\mathrm{PhD}$ mathematicians.

Some fellows choose to remain in the federal space or private industry after the fellowship and continue in policymaking. There are fellows who return to academia with a diverse view of the needs of the federal government and the US which informs their research. They are better equipped with knowledge of the policies which make our government function and the impact these policies may have when implemented.

-Carla Cotwright-Williams, 2012-2013 AMS/AAAS Congressional Fellow 
For more information about...

AAAS membership, see aaas.org/membership

AAAS Fellows, see aaas.org/fel1ows

AAAS Science and Technology Policy Fellowships, see www.aaas.org/programs/science-technology -policy-fellowships

AMS Congressional Fellowship, see www.ams.org/programs/ams-fel1owships/ams-aaas/ams-aaas -congressiona1-fe11owship

AAAS annual meeting, see meetings.aaas.org

AAAS Section A, see aaas.org/governance/section-a

ists available. "I very much want to see more applications from the math community," she said.

\section{Mathematics Symposia}

The AAAS Annual Meeting bills itself as "the world's largest general scientific gathering," and Section A secretary Reinhard Laubenbacher's informal polling of members of the math community indicates widespread belief that, to put it mildly hyperbolically, "there are never any symposia in

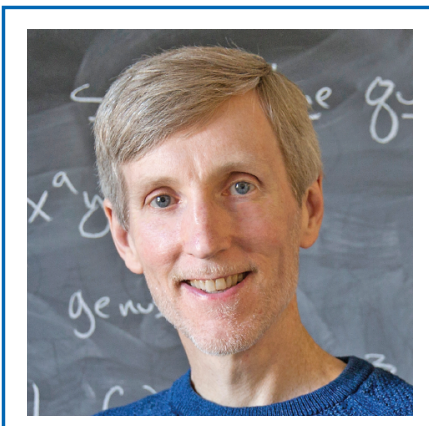

As we move forward into the twenty-first century, mathematicians are facing new research challenges that scientists have been dealing with for years. For example, large-scale collaborations are becoming more common in mathematics, and computational tools are playing an increasingly important role, both as generators of large data sets and tools for analyzing them. Communication with the public is another area that mathematicians have really only started to think seriously about quite recently, whereas scientists have been grappling with this issue for years.

As mathematicians, we often approach these problems from a different point of view than scientists, and in many cases we are facing them for the first time. Sharing a fresh perspective is useful for both scientists and mathematicians; we can learn from each other's experiences.

I would encourage any mathematician who is given the opportunity to consider presenting at the AAAS. We have some interesting stories to tell, and it is a great opportunity to make connections with people that you might not meet at any other venue.

-Andrew Sutherland, Massachusetts Institute of Technology, presented symposium "Closing the Gap: The Polymath Project on Bounded Gaps Between Primes" at the AAAS 2016 Annual Meeting mathematics at these meetings." In fact the 2019 meeting included four scientific symposia officially classified as mathematics. "If you put them together cumulatively," Laubenbacher noted, "there's a whole day's worth of mathematics you can go to." And since three of the four 2019 symposia were discussed at the 2018 Section A business meeting, generating ideas for future sessions was a priority for the 2019 convening.

Individuals submit session proposals, but each section endorses one proposal, and section endorsement vastly increases a proposal's chances of acceptance. Possible topics bandied about included the Riemann hypothesis, mathematics and gerrymandering, the mathematics of artificial intelligence, and math for social justice. Meeting attendees committed to pitching potential presenters. (See MIT mathematician Andrew Sutherland's statement, left, for his thoughts on presenting at AAAS.) Laubenbacher offered to help craft proposals, ${ }^{2}$ expressing his aspiration for incremental growth in the visibility of mathematics at the meeting: "Hopefully next year we will have five symposia rather than four."

\section{Tremendous Impact}

Mathematicians who would like to organize a symposium-or, to choose but one of AAAS's numerous initiatives, participate in a science communication workshopmay not be aware that the opportunity exists. The primary takeaway from the business meeting of the Section on Mathematics was that each attendee should spread the word about AAAS activities to his or her corner of the mathematics community.

A Section A web presence is in the offing, but until it goes live, information will be disseminated via other channels, such as blog posts (see, for instance, https://bit. 7y/2TToM9c), slide presentations at regional meetings, announcements in society publications.

"Everybody should do as much as they can," Laubenbacher urged. "Collectively we could make a tremendous impact."

\footnotetext{
${ }^{2}$ The deadline for proposals for the 2020 meeting has passed. No harm, however, in getting a head start on crafting a winning proposal for 2021.
} 


\section{Feed Their Curiosity}

Laubenbacher (1 aubenbacher@uchc . edu) welcomes correspondence from Notices readers interested in any sort of involvement with AAAS and Section A. He is particularly keen for mathematicians to consider contributing to Science (which is published by AAAS). Many Science articles are heavily mathematical, but the journal seldom publishes mathematics research per se. Pieces about math and mathematicians do make an occasional appearance, however. "To me this indicates that the science community is curious about us," says Laubenbacher.

And why not feed that curiosity? Mathematical scientists could contribute to the journal in any number of ways, from a research article to a perspective piece to a policy forum. "Probably the most effective way at this time," says Laubenbacher, "would be to write an appropriate review of a math topic or open problem."

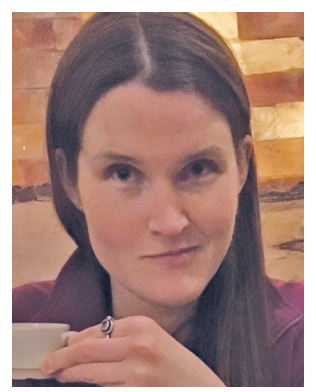

Sophia D. Merow

\section{Credits}

Photo of Eric Friedlander is courtesy of Eric Friedlander. Photo of Carla Cotwright-Williams is courtesy of SSA.

Photo of Andrew Sutherland is courtesy of Andrew Sutherland.

Author photo is by David Gabel. 